\title{
A EKPHRASIS DAS ARMAS DE AQUILES NA OBRA PÓS-HOMÉRICA DE QUINTO DE ESMIRNA
}

\author{
Erika Mayara Pasqual* \\ Universidade de São Paulo
}

\begin{abstract}
Resumo. O estudo apresenta uma tradução comentada da ekphrasis das armas de Aquiles, situada no Livro V (vv. 6-120) da epopeia Pós-Homérica de Quinto de Esmirna, composta no Período Imperial entre os séculos III e IV d.C. Querendo se inserir na tradição épica, especificamente "ser como Homero", Quinto busca aproximar-se e, ao mesmo tempo, inovar-se em relação ao que é narrado nas obras homéricas. À vista disso, comparo em notas as descrições das armas feitas no Livro V com a mesma cena presente na Ilíada XVIII 478-613, a fim de expor as semelhanças e as diferenças entre as duas obras.
\end{abstract}

Palavras-chave. Poesia épica; ekphrasis; escudo; Quinto de Esmirna.

D.O.I. 10.11606/issn.2358-3150.v19i1p152-161

Quinto de Esmirna é um representante da poesia épica do Período Imperial que teria vivido entre os séculos III e IV d.C., conforme as informações retiradas da sua própria obra Pós-Homérica (12.306-13). Segundo Toledo Vargas (2004,12), Quinto é um instruído leitor formado em bibliotecas e escolas, onde pode ter acesso aos grandes escritores da tradição literária anterior e, a partir deles, compor seu próprio poema. Querendo se inserir na tradição épica, a Pós-Homérica se propõe como uma continuadora das obras homéricas (especificamente preenche a lacuna cronológica entre a Ilíada e a Odisseia), apresentando uma assimilação mais próxima possível da língua, estilo e métrica do seu modelo épico canônico. ${ }^{1}$ Entretanto é inegável também que haja divergências de recursos estilísticos, linguísticos, recriações ou inovações dentro do seu fazer poético mimético, ${ }^{2}$ visto que ele se encontra afastado séculos de distancia de Homero e é influenciado pelo seu contexto histórico e instrução múltipla. ${ }^{3}$

\footnotetext{
Mestranda em Letras Clássicas pela Universidade de São Paulo. Bolsista CAPES.

*Artigo recebido em 05.ago.2016 e aceito para publicação em 28.out.2016.

${ }^{1}$ Cf. Garcia Romero 1986, 109.

${ }^{2}$ Cf. Garcia Romero 1989, Maciver 2012.

${ }^{3}$ Cf. Vian 1959.
} 
A narrativa Pós-Homérica $(\mathrm{PH})$ é interrompida três vezes para a $e k$ phrasis em larga proporção de um armamento bélico (Livro v: o escudo de Aquiles; Livro vi: o escudo de Eurípilo; Livro Ix: as armas de Filoctetes). Contudo o interesse deste estudo é analisar apenas a descrição das armas de Aquiles ( $P H$. 5.6-120) por este se aproximar e, ao mesmo tempo, inovar em relação ao que é narrado na Ilíada xviıI (478-613). Nas palavras de Maciver $(2012,42)$, "It becomes clear that the shield of Achilles in the Posthomerica exhibits strong originality, despite being the same artefact described in the Iliad, and while still managing to stay based structurally on its model". Quinto de Esmirna, portanto, elabora uma nova interpretação a partir da descrição ecfrástica já conhecida por seu público, ${ }^{4}$ explorando uma singular representatividade da presença do escudo de Aquiles na narrativa.

A deusa Tétis, na Ilíada XvıII, é responsável por entregar a Aquiles o armamento criado por Hefesto para que retornasse à guerra. Contudo, na Pós-Homérica, Tétis aparece agora para conceder as armas divinas àquele que salvou o corpo do seu filho, quando morto em combate (PH. 5.1-5). A ekphrasis do narrador Quinto não descreve o processo de criação do escudo, como há em Homero, somente o objeto já construído. O leitor homérico reconhece similaridades entre o escudo da Ilíada e o da Pós-Homérica, porém não há uma reprodução das figuras já representadas, além disso há outras fontes literárias anteriores influenciadoras que contribuíram para a composição de Quinto. ${ }^{5}$

Deixando a análise minuciosa das figuras descritas no escudo para mais adiante como notas da tradução, o contexto em que o armamento aparece no Livro v desvincula-se do que há em Homero. O escudo de Aquiles na Ilíada XVIII (478-608) é um objeto importante para a sequência narrativa, pois representa a decisão do guerreiro de voltar para a guerra motivado pelo desejo de vingar a morte de Pátroclo. Assim como a presença do herói na batalha é crucial $^{6}$ aos aqueus para que não sejam vencidos pelo inimigo, sua imagem é exaltada pela sua armadura que comporta todo seu esplendor e superioridade, disseminando seu poder no olhar do outro, não apenas pela sua ação em guerra. No entanto, Quinto de Esmirna coloca o armamento bélico como um prêmio de uma disputa retórica entre Odis-

\footnotetext{
${ }^{4}$ Maciver (2012, 39-66) faz um estudo detalhado sobre o uso da ekphrasis do escudo de Aquiles por Quinto de Esmirna.

${ }^{5}$ Cf. Vian 1959.

${ }_{6}$ "Como observa muy bien Schadewaldt, em su agudo y profundo comentario al pasaje, La ékphrasis del escudo señala el momento crucial en que Aquiles depone su actitud de no combatir para empuñar de nuevo las armas, com la doble certidumbre de que va a dar muerte al más odiado de sus enemigos, pero también de que a cambio de esa satisfacción va a perder el más precioso de los dones: el de su propia vida. El momento bien merecía, pues, um punto de reposo." (Blanco 1986, 1).
} 
seu e Ájax, assegurando ao vencedor honra e reconhecimento dos feitos em guerra. Esse aspecto de escudo como uma recompensa pelo trabalho realizado fica evidente quando Ájax é tomado por uma fúria e anseia vingar-se ao terem sido menosprezados seus feitos por todos os aqueus no momento em que não recebeu a vitória, motivando seu suicídio ( $P H .5 .322-663)$.

A representatividade da ekphrasis na narrativa Pós-Homérica abre precedente para entender o desenrolar da guerra de Troia, que não será encerrada somente por meio das lutas como outrora, mas sim a partir de um plano ardiloso de Odisseu (a construção do cavalo de madeira). Com isso, a aquisição do exuberante escudo dado ao vitorioso Odisseu pode ser entendida como a caracterização do novo tipo de herói que será temível para o inimigo: o movido pela astúcia, não apenas pela força.

\title{
TRADUÇÃO DA EKPHRASIS DAS ARMAS DE AQUILES (PH. 5.1-120)
}

\begin{abstract}
Mas quando os numerosos jogos chegaram ao fim, então as armas divinas de Aquiles, de grande coragem, a deusa Tétis colocou no centro. E por toda parte resplandecia o relevo ornamentado tal qual a força de Hefesto fez ao redor do escudo do valente Eácida. ${ }^{7}$ Primeiro foi bem ornado sobre a obra de um deus o céu e o éter e, simultaneamente, na terra jazia o mar. Ali os ventos e as nuvens, a lua e o sol se distinguem cada um em seu lugar; e todas constelações foram confeccionadas tão numerosas que se movem em volta girando pelo céu. ${ }^{8}$ E logo abaixo deles o infinito ar igualmente espalhava-se; e, por ele, as aves de longos bicos sobrevoavam ao redor: dirias que são levadas pelos ventos parecendo vivas. Ao redor foram confeccionadas Tétis ${ }^{9}$ e a profunda corrente do Oceano; e imediatamente os cursos dos penosos rios derramavam-se
\end{abstract}

${ }^{7}$ A narrativa é interrompida para a ekphrasis das armas de Aquiles, confeccionadas por Hefesto a pedido da mãe do guerreiro na Ilíada 18.429-77. Embora essa cena apareça na obra homérica (Il. 18.478-613) com a mesma descrição minuciosa dos relevos forjados na superfície do armamento, Quinto de Esmirna não faz uma cópia fidedigna, mas descreve imagens diferenciadas, aludindo algumas cenas do escudo homérico. De certo, o uso da ekphrasis é recorrente no gênero épico, por isso Quinto pode se servir de diversos outros modelos para criar a imagem descrita nas armas de Aquiles em sua obra, contudo não é de interesse deste artigo apresentar outras influências além da homérica.

${ }^{8} \mathrm{Na}$ Ilíada, a descrição do escudo começa com a definição do material usado e sua composição por ser o momento em que fora forjado, por isso não cabe essa menção em Quinto. A primeira imagem a ser descrita coincide com a que aparece em Homero (Il. 18.483-89) ao apresentar os elementos astrológicos e da natureza. Entretanto escudo de Quinto apresenta uma definição mais longa (PH. 5.6-16) com a presença de aves dando a aparência de movimento na cena, seguindo com o surgimento das correntes circulares que circundam a terra.

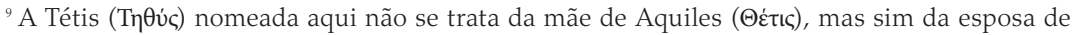
Oceano e mãe dos Rios e das Oceânides.

Let. Cláss., São Paulo, v. 19, n.1, p.152-161, 2015 
circundamente, cada um do seu lado, girando entre a terra. ${ }^{10}$

Assim, ao redor, foram bem ornados junto aos altos montes

terríveis leões e impudentes chacais; ali havia também

ursas penosas e panteras; e ficavam junto a elas

poderosos javalis afiando, sob as firmes mandíbulas,

com ruído, suas mais penosas presas que ressoam forte.

Ali uns caçadores atrás conduziam o vigor dos cães,

enquanto outros, lançando pedras e dardos velozes,

por sua vez, lutavam face a face, como na realidade. ${ }^{11}$

Então ali as guerras ${ }^{12}$ destruidoras de homens e também

tumultos violentos encontravam-se. As tropas estavam mortas

mescladas entre seus velozes cavalos: toda terra em muito sangue

parecia banhada sobre o invencível escudo.

Também ali estão Temor e Medo e a funesta Enio,

tendo eles todos os membros jorrando em sangue infeliz;

Ali estão a funesta Éris e as Erínias de poderosos ânimos:

uma excitando os homens a marchar para o tumulto indomável,

e as outras soprando um odor de fogo destrutivo.

Ao redor, as amargas Ceres lançavam-se e, lá entre elas,

vagava o vigor do infeliz Tânatos; então, ao redor dele,

encontravam-se os Combates terríveis, dos quais por toda parte

o sangue e o suor caiam desde os membros até o chão. ${ }^{13}$

Ali também estavam as impudentes Górgonas ${ }^{14}$ : em volta delas

terríveis serpentes agitavam-se ao redor dos seus cabelos

vibrando as línguas de forma medonha. Uma maravilha infinita

eram aqueles relevos, levando um grande medo aos homens,

porque eram semelhantes ao seres dotados de movimentos.

E estas foram todas as monstruosidades bélicas confeccionadas.

E à parte estavam os trabalhos da magnífica Paz. ${ }^{15}$

\footnotetext{
${ }^{10} \mathrm{~A}$ partir desse verso, Quinto passa a descrever cenas bélicas que serão contrapostas com situações que regem a paz. Essa diferenciação só é explicitada nos versos 43 e 44, enquanto a obra homérica informa inicialmente a presença das duas cenas opostas (Il. 18.489-90), caracterizadas como duas cidades.

${ }^{11}$ Entre os versos 16 ao 24, há animais selvagens habitando montanhas e uma caçada em andamento de homens com seus cães. Esta cena não é descrita em Homero, apenas uma similar em que quatro pastores com seus nove cães são surpreendidos pelo ataque violento de dois leões a um boi (Il. 18.573-86).

${ }^{12}$ Há uma descrição das imagens monstruosas que agem nos conflitos, assim como as divindades e seres míticos que regem esse ambiente hostil entre os versos 25-43 (PH. 5).

${ }^{13}$ Quinto de Esmirna ilustra esta cena introduzindo inúmeras alegorias bélicas: Temor e o Medo (filhos de Ares); Enio (deusa da guerra), Éris e as Erínias; as Ceres (filhas da Noite) e Tânatos; e, por fim, os Combates. No escudo de Homero, as imagens representativas são em suma diferentes (v. 509-40): é descrito o ataque de um exército a uma cidade, a qual se prepara para resistir, havendo ali a presença divina registrada por Ares e por Atena neste embate; Éris, Discórdia, o Tumulto e a Ceres estão envolvidos em um combate e rodeados por cadáveres e sangue, semelhante ao que aparece em Quinto.

${ }^{14}$ As Górgonas não estão associadas aqui com a guerra nem com a morte, apenas foram retratadas por sua natureza monstruosa capaz de amedrontar os homens.

${ }^{15}$ Invertendo a ordem presente na Ilíada 18, Quinto descreve primeiro a cena de guerra e depois, a da paz.
} 
Em volta, numerosas classes de homens muito sofredores

habitavam belas cidades; e a Justiça olhava fixo tudo ${ }^{16}$ :

cada um levava as mãos para um trabalho; E ao redor

as lavouras carregavam-se de frutos; e a negra terra florescia.

Escarpadíssimo e rochoso, fora confeccionado sobre a obra divina

o monte da sagrada Virtude; e ali também ela

ficara em pé pisando sobre a extremidade da palmeira,

tão alta que tocava o céu. E por toda parte,

as veredas, divididas por numerosos espinhos,

afastavam dos homens o bom caminho, já que muitos

retiravam-se doravante atônitos com as estradas íngremes,

e uns poucos banhados de suor ascendiam à rota sagrada.

E ali estavam os ceifadores indo pelo extenso sulco,

apressados com suas foices recém-afiadas, e com suas mãos

obtinham a colheita seca; havia muitos outros ceifeiros

seguindo: assim o trabalho desenvolvia-se cada vez mais.

Ali os bois, tendo sempre os pescoços sob os jugos

arrastavam, uns, as pesadas carroças carregadas de espigas

com as réstias, enquanto outros, por sua vez, lavravam o solo,

e atrás deles o terreno enegrecia; homens fortes seguiam-lhes

conduzindo os aguilhões bovinos entre suas mãos

alternadamente: revelava assim um imenso trabalho. ${ }^{17}$

Ali flautas e cítaras havia em grandes banquetes;

os coros de mulheres fixavam-se ao lado dos pés dos jovens:

elas estavam se movimentando semelhantes aos seres vivos. ${ }^{18}$

Mas, então, perto da dança e da alegria agradável,

emergia do mar (tendo espuma ainda ao redor dos cabelos)

a Cípris de bela coroa, e o Desejo cobiçava-a

sorrindo amável junto às Graças de belos cabelos.

Ali então estavam as filhas de Nereu corajoso

que do mar imenso conduziam sua irmã

para sua boda com o valente Eácida. ${ }^{19}$ Ao redor, todos

os imortais banqueteavam ${ }^{20}$ sob cume elevado de Pélion;

em torno estavam os úmidos e fecundos prados,

tendo sido ornados com infinitas flores de verão,

bosques e fontes transparentes com boa água.

${ }^{16} \mathrm{~A}$ presença da Justiça olhando tudo pode aludir à cena homérica de um julgamento (Il. 18.496-509).

${ }^{17}$ Há cenas similares em Homero com homens trabalhando nos campos, arando, plantando e colhendo, sendo ajudados por seus bois (Il. 18.541-72).

${ }^{18}$ Quinto apresenta em poucos versos uma suposta festa com músicas e mulheres dançando, já Homero descreve mais detalhadamente um grande evento festivo em honra a Ariadne (Il. 18.590-606).

${ }^{19}$ No escudo de Quinto, as bodas descrita são da própria Tétis, a qual é acompanhada por suas irmãs ao casamento com o Eácida; em oposição, na obra homérica é apresentada uma festa nupcial de muitas noivas anônimas que agitam as ruas da cidade.

${ }^{20} \mathrm{~A}$ imagem do banquete aparece em Quinto, sendo feito pelas divindades à parte dos homens; em Homero é exibida a preparação da refeição envolvendo diversas pessoas na propriedade de um rei (v. 556-60). 
E as naus navegavam sobre o mar funesto:

umas em transversal se lançando, outras indo em linha reta;

sobre elas uma penosa onda crescia intensificando-se.

Os atônitos marinheiros, cada um por um lado,

temiam os ventos impetuosos, como na realidade,

puxando as brancas velas, para que fugissem da morte;

e outros assentavam-se sobre os remos esforçando-se; em torno

às naus movidas pelos remos, o mar negro embranquecia-se.

Junto a eles, radiante entre os animais marinhos,

ornava-se o Treme-terra: seus cavalos de pés rápidos,

como na realidade, carregavam-no apressados sobre o mar

golpeados pelo chicote dourado; e quando se lançam, ao redor, as ondas aplainavam-se, então havia uma calmaria plana adiante. De cada lado, em grupos, ao redor do soberano os golfinhos reunidos alegravam-se sem limites agitando a cauda ao rei: ao longo da grande onda tenebrosa do mar aparentavam estarem nadando, ainda sendo pratas. ${ }^{21}$ Assim inúmeras cenas habilmente jazem sobre o escudo pelas imortais mãos de Hefesto, de sensato espírito.

Então a profunda correnteza do Oceano circundava a tudo, pois estava sob a borda de fora, na qual todo escudo fixava-se; e assim todos os relevos foram atados. ${ }^{22}$

Junto a ele acomodava-se o capacete grandemente pesado. Zeus fora confeccionado nele com aparência bem zangada, subindo ao céu; os imortais em torno suportavam fadigas, unindo-se à Zeus, enquanto os Titãs travavam um conflito. E um forte fogo já os envolvia; e raios incessantes, semelhantes às nuvens, eram lançados do céu, pois uma implacável força erguia-se de Zeus; então eles ainda exalavam parecendo queimados. Ao redor, reclinara também a cavidade da couraça muito invulnerável e sólida, a qual comportava o Pelida.

E as extraordinárias cnêmides foram ornadas: eram leves somente para Aquiles, mesmo sendo muito firmes.

Bem perto a irresistível espada resplandecia abundantemente, sobressaindo-se pela correia dourada e pela bainha prateada, sobre a qual a empunhadura, guarnecida de marfim, distinguia-se entre as divinas armaduras resplandecendo. Junto a estas, acomodava-se a vigorosa lança sob a terra, a Pelíada, igualando-se ao abeto de folhagem elevada, que ainda exalava o cruor e o sangue de Heitor. ${ }^{23}$

${ }^{21}$ Não há algo similar na Ilíada 18 sobre as cenas marinhas descritas por Quinto (PH. 5.80-96).

${ }^{22}$ Assim como Homero (Il. 18.607-9), Quinto encerra a descrição do escudo com as correntes do Oceano à extrema borda do armamento.

${ }^{23}$ Diferente de Homero que faz uma breve citação dos demais armamentos de Aquiles (II. 18.609-13), há a ekphrasis também do capacete do herói no Livro V (v. 102-9), representando toda a Titanomaquia; em seguida, Quinto apresenta as demais armas e seu material de composição, distinguindo-as de qualquer outra (PH. 5.110-20). 
TA ME@”OMHPON. $\Lambda$ OYO $\Sigma$ E' 1-120

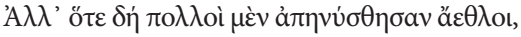

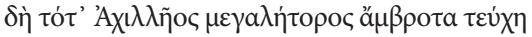

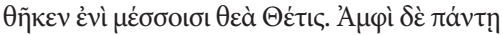

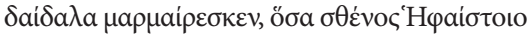

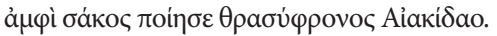

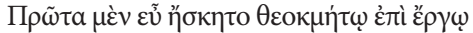

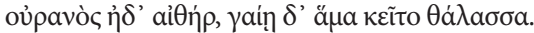

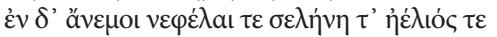

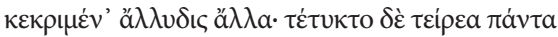

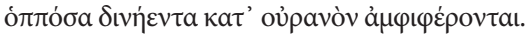

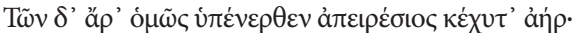

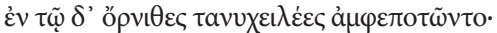

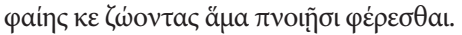

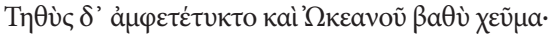

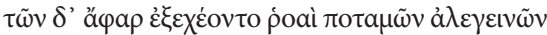

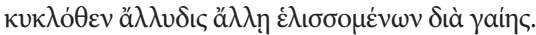

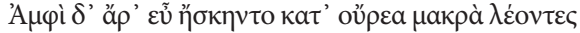

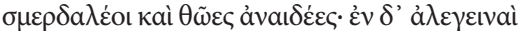

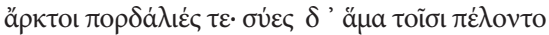

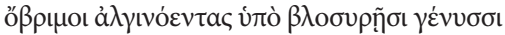
$\theta \eta \dot{\gamma o v \tau \varepsilon \varsigma ~ \kappa a v a \chi \eta \delta o ̀ v ~ \varepsilon ̇ v \kappa \tau u \pi \varepsilon ́ o v \tau a c ~ o ̉ \delta o ́ v \tau a c . ~}$

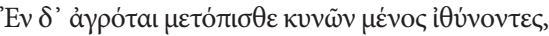

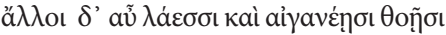

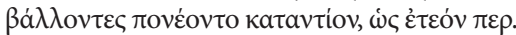

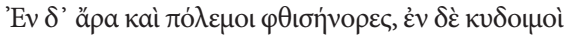

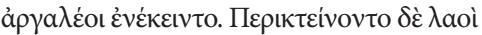

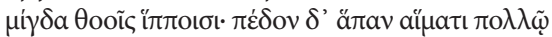

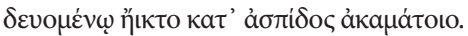

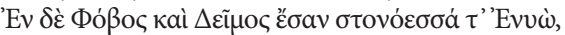

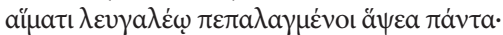

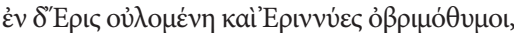

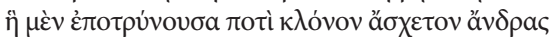

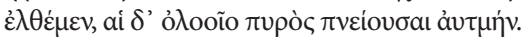

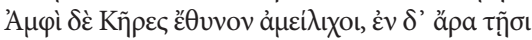

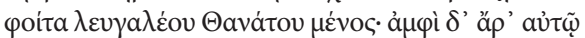

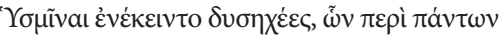

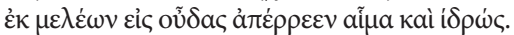

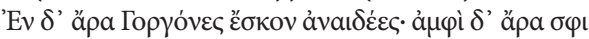

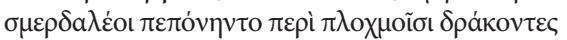

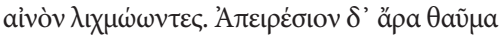

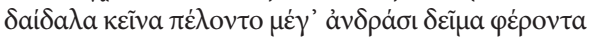

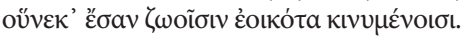

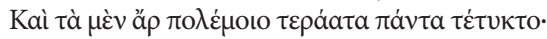

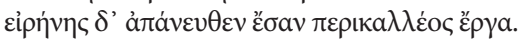

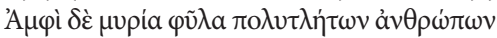

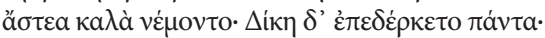

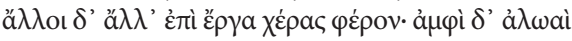




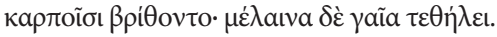

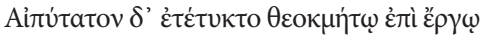

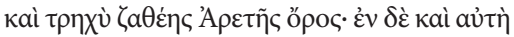

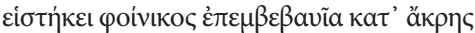

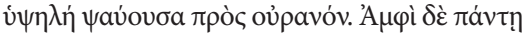

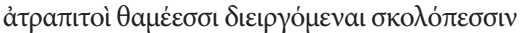

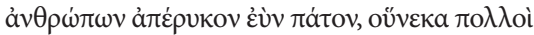

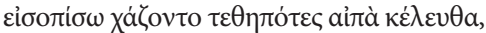

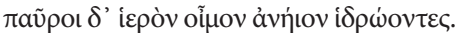

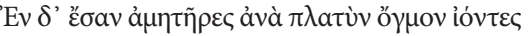

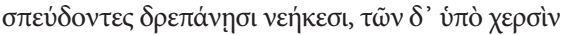

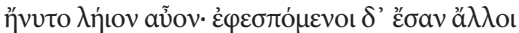

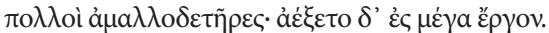

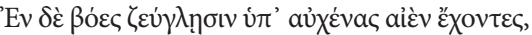

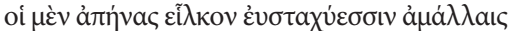

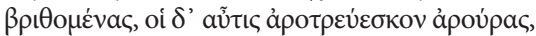

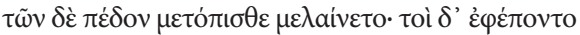

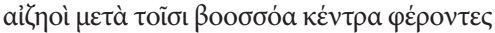

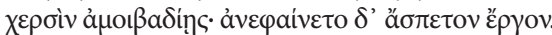

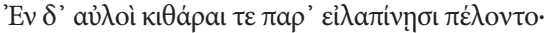

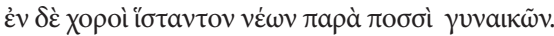

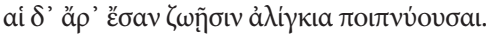

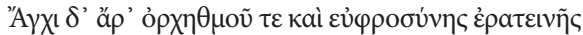

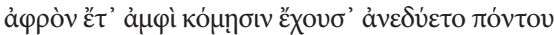

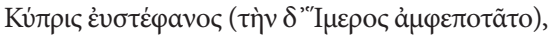

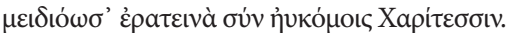

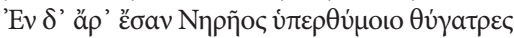

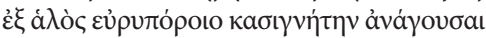

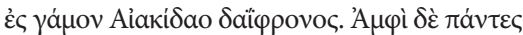

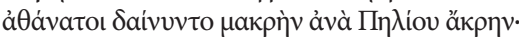

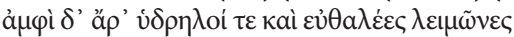

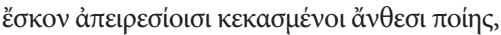

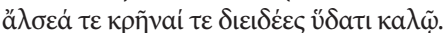

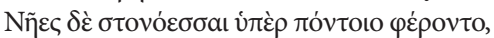

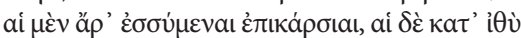

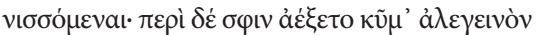

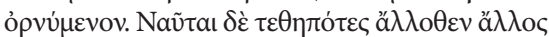

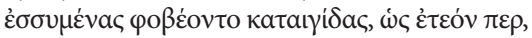
$\lambda \alpha i \varphi \varepsilon \alpha \lambda \varepsilon v \dot{\kappa}$ '

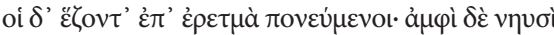

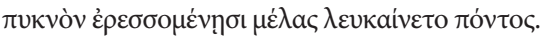

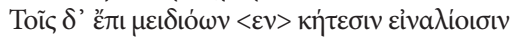

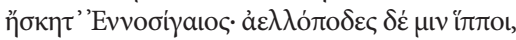

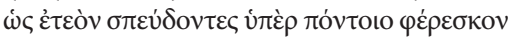

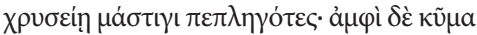

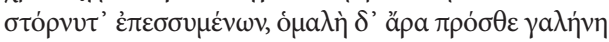

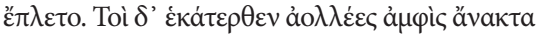

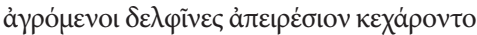

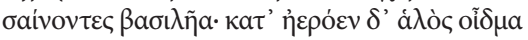




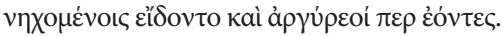

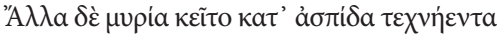

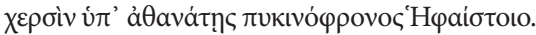

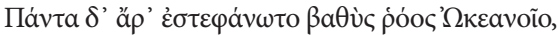

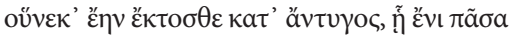

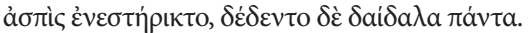

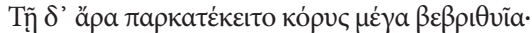

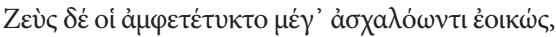

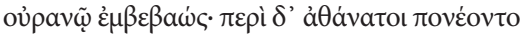

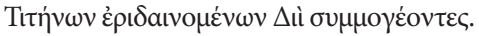

Toù $\delta$ '

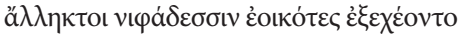

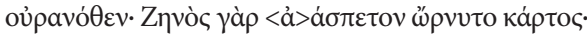

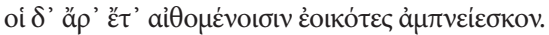

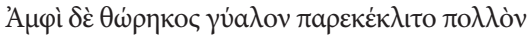

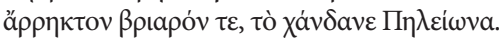

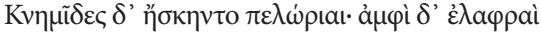

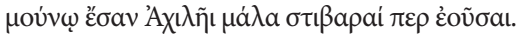

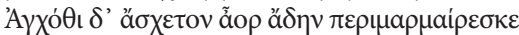

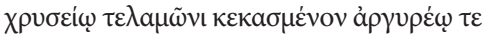

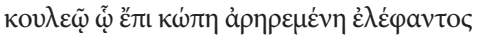

$\theta \varepsilon \sigma \pi \varepsilon \sigma \dot{o}$

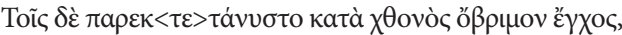

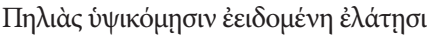

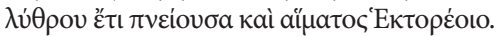

\section{REFERÊNCIAS}

Blanco Freijeiro, Antonio. 1986. "El Escudo de Aquiles." Historia 16(121):153-50.

García Romero, Francisco A. 1986. "La 'intervención psíquica' en los Post Homerica de Quinto de Esmirna." Habis 17:109-16

García Romero, Francisco A. 1989. “Las glosas homéricas en Quinto de Esmirna. Unas notas sobre Calímaco y Quinto a propósito de ES IPPON KETOENTA (QS XII 314)." Habis 20:33-6.

García Romero, Francisco A. 2001. Being Greek under Rome: Cultural Identity, the Second Sophistic and the Development of Empire.Cambridge: Cambridge University Press.

Maciver, Calum Alasdair. 2012. Quintus Smyrnaeus' Posthomerica: Engaging Homer in Late Antiquity. Mnemosyne supplements. Monographs on Greek and Latin language and literature, 343. Leiden; Boston: Brill.

Papanghelis, Theodore D.; Rengakos, Antonios. 2001. A companion to Apollonius Rhodius. Brill, Leiden.

Pompella, Giuseppe. 1981. Index in Quintum Smyrnaeum. Hildesheim.

Vian, Francis. 1954. "Les Comparaisons de Quintus de Smyrne." RPh 28:30-51. 
Vian, Francis. 1959. Recherches sur les Posthomerica de Quintus de Smyrne. Collection Études et Commentaires, XXX. Paris, Klincksieck.

Vian, Francis. 1963. Quintus de Smyrne, La suite d'Homère. Texte établi et traduit par V. Francis. Paris: Les Belles Lettres (Collection des universités de France). Tome I: Livres I-IV.

Vian, Francis. 1966. Quintus de Smyrne, La suite d'Homère. Texte établi et traduit par V. Francis. Paris: Les Belles Lettres (Collection des universités de France). Tome II: Livres V-IX.

Title. The ekphrasis of Achilles' weapons in Quintus of Smyrna's Posthomerica.

Abstract: This study presents an annotated translation of the ekphrasis of Achilles' weapons, in Book V (v. 6-12) of Quintus of Smyrna's epic poem Posthomerica, composed in the Empire Period between the $3^{\text {rd }}$ and $4^{\text {th }}$ centuries A.D. Aiming to insert himself on the epic tradition, more specifically, "being like Homer", Quintus seeks to approach and, at the same time, innovate regarding the themes narrated on the Homeric works. Considering this, I compare in notes the descriptions of the weapons in Book V with the same scene in the Iliad XVIII 478-613 to expose the similarities and differences between the two poems.

Keywords. Epic poetry; ekphrasis; shield; Quintus of Smyrna. 